\title{
The association of dietary fibres with glucose tolerance is partly explained by concomitant intake of thiamine: The Hoorn Study
}

\author{
S.J.L. Bakker ${ }^{1}$, E. K. Hoogeveen ${ }^{2}$, G. Nijpels ${ }^{2}$, P.J. Kostense ${ }^{2,3}$, J.M. Dekker ${ }^{2}$, R. O. B. Gans ${ }^{1}$, R.J. Heine ${ }^{1,2}$ \\ ${ }^{1}$ Institute for Endocrinology, Reproduction and Metabolism, University Hospital Vrije Universiteit, Amsterdam \\ ${ }^{2}$ Institute for Research in Extramural Medicine, Vrije Universiteit, Amsterdam \\ ${ }^{3}$ Department of Epidemiology and Biostatistics, Vrije Universiteit, Amsterdam
}

\begin{abstract}
Summary Epidemiologic studies have shown an association between the intake of dietary fibres and 2-h glucose values. Food rich in dietary fibres is often also rich in thiamine. Animal studies have shown that thiamine deficiency can induce glucose intolerance. Our aim was to investigate the association between fibre consumption and thiamine intake on the one hand and glucose tolerance on the other hand. We used data from the Hoorn Study, a study of glucose tolerance among 1008 men and 1188 women, aged 50-75 years, without diabetes. In linear regression analyses, fibre intake was inversely associated with fasting glucose. There was also an inverse association between fibre intake and 2-h glucose but it disappeared for the greater part after adjustment for fasting glucose. Fibre intake appeared to be strongly correlated with thiamine intake, and this correlation
\end{abstract}

explained the remaining part of the association between fibre intake and 2 -h glucose. Thiamine intake appeared to have a strong and relevant association with 2-h glucose, which was independent of fibre intake and fasting glucose. This association was borderline after adjustment for potential confounders. In women, but not in men, the effect of thiamine intake on 2-h glucose seemed to be modified by fibre intake, independent of potential confounders. In conclusion, part of the association between fibre intake and glucose tolerance is possibly attributable to concomitant thiamine intake. [Diabetologia (1998) 41: 1168-1175]

Keywords Dietary fibre, thiamine, thiamine deficiency, glucose tolerance test, sex, insulin resistance, human
Intervention studies have convincingly shown that high fibre diets decrease postprandial glycaemia in diabetic subjects [1]. This beneficial effect has been attributed to the capacity of dietary fibres to retard the uptake of nutrients from the gastrointestinal tract [1]. Studies that used an oral glucose tolerance test found, however, the same inverse association of habitual intake of dietary fibres with fasting and postload glucose values in general populations and nondiabetic subjects [2-8]. In these studies physicochemical properties of fibre cannot explain lower post-load glucose values as the fibres are not present at the time

Received: 30 December 1997 and in revised form: 16 June 1998

Corresponding author: S.J.L. Bakker, M.D., Department of Endocrinology, Academic Hospital Vrije Universiteit, P.O. Box 7057, 1007 MB Amsterdam, The Netherlands of the oral glucose tolerance test. One mechanism that seems to be involved in this controversy is that a high intake of dietary fibres appears to enhance the sensitivity of peripheral tissues to the action of insulin $[5,9]$. Another factor that could be involved is co-ingestion of thiamine with fibre containing substances.

Thiamine is present in high amounts in fibre-containing foods such as whole grain products, unprocessed rice and legumes [10]. Three key enzymes of glucose metabolism are thiamine-dependent, namely, pyruvate dehydrogenase, a-ketoglutarate dehydrogenase and transketolase [11-13]. Thiamine deficiency results in an overall reduction in the use of glucose by tissue $[14,15]$, and an impairment of the production and secretion of insulin by beta cells [16-19]. Although thiamine deficiency can induce high fasting blood glucose concentrations together with low serum insulin concentrations in laboratory animals 
[19], post-load glucose metabolism may be more severely affected as a consequence of a reduced maximum metabolic flux of glucose through thiamine-dependent enzymes combined with beta-cell dysfunction. This is confirmed by studies that showed an overt glucose intolerance in thiamine-deficient laboratory animals with normal fasting blood glucose concentrations [20,21]. It is not known whether variation of thiamine intake influences glucose tolerance in a general population [10, 22].

The aims of the present study were to investigate the association between thiamine intake and fibre intake and their relative contributions to glucose tolerance in the men and women of the Caucasian population in the Hoorn Study.

\section{Subjects and methods}

Study population. The study population consisted of Caucasian men and women, aged 50 to 74 years, randomly selected from the registry office of the medium-sized town of Hoorn in the Netherlands. This town has approximately 59,000 inhabitants. A cross-sectional survey of glucose tolerance took place from October 1989 to December 1991. From the 3,553 subjects inivited 2,484 eligible subjects participated (70\%). They underwent a $75 \mathrm{~g}$ Oral Glucose Tolerance Test (OGTT) and were classified according to the 1985 WHO criteria [7]. The study protocol of the Hoorn study [23] was approved by the ethics committee of the 'Academic Hospital Vrije Universiteit' and written informed consent was obtained from all participants.

For this study, subjects with known diabetes or newly diagnosed diabetes (92 men, 130 women) were excluded from further analysis. An additional 43 men and 23 women were excluded because of missing data on thiamine and fibre intake, leaving 1008 men and 1188 women eligible for analysis. At physical examination, height and weight were measured without shoes and outer garments. BMI was calculated as weight (in $\mathrm{kg}$ ) divided by height $\left(\mathrm{m}^{2}\right)$. Waist-to-hip ratio was measured by a standardised method [24]. Dietary habits and alcohol intake were measured by a semi-quantitative food frequency questionnaire [25]. The conversion from foodstuffs to energy and nutrient intakes was established with a computerized version of the Dutch Food Composition Table [25]. This food composition table cannot differentiate between soluble and insoluble dietary fibre, thus giving the total fibre intake. This variable was used in all analyses in which dietary fibres are included. Insulin concentrations were measured fasting in all subjects and at $2 \mathrm{~h}$ after glucose ingestion in randomly selected men $(n=242)$ and women $(n=264)[23]$.

Laboratory analysis. All analyses were done in the University Hospital Laboratory of the Vrije Universiteit Amsterdam. Fasting and 2-h blood specimens were obtained. Plasma glucose concentrations were determined on the same day and serum was stored at $-20^{\circ} \mathrm{C}$ for subsequent assessment of serum insulin concentrations. Glucose was measured with a glucose dehydrogenase method [Merck, Darmstadt, Germary: interassay coefficient of variation $(\mathrm{CV}): 1.4 \%]$. Immunospecific insulin was measured in serum by a double-antibody radioimmunoassay (Lot SP 21, Linco Research, St. Louis, USA). The inter-assay $\mathrm{CV}$ was $6 \%$ at insulin concentrations in the range of $40-1000 \mathrm{pmol} / \mathrm{l}$. The lower limit of sensitivity was $12 \mathrm{pmol} / \mathrm{l}$. Fasting serum cholesterol and HDL-cholesterol were mea-
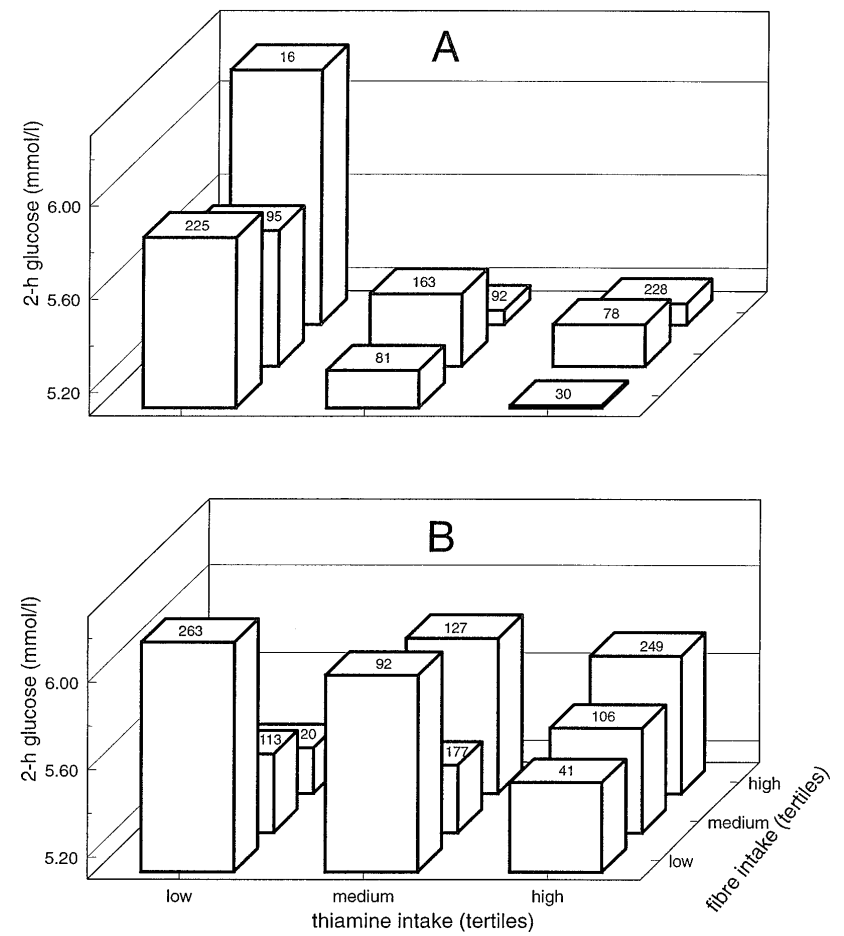

Fig. 1A, B. Two-hour glucose values in tertiles of thiamine and fibre intake in 1008 men (A) and 1188 women (B). The number of subjects in each segment is given on top of the boxes

sured with the enzymatic colorimetric method (CHOD-PAP, Boehringer Mannheim, Germany). Fasting serum triglycerides were measured using an enzymatic colorimetric method as well (CPO-PAP, Boehringer Mannheim, Germany).

Statistical analysis. As a measure of glucose tolerance the glucose values obtained $2 \mathrm{~h}$ after the $75 \mathrm{~g}$ oral glucose load were used. To analyse the potential relevance of thiamine intake and fibre intake as determinants of 2-h glucose, we first made graphical representations of the associations for both sexes separately (Fig.1). Subsequently, linear regression analyses were performed for both sexes separately. At first crude (univariate) analysis was done (Tables 1 and 2, columns with fibre and thiamine intake alone). Then thiamine intake and fibre intake were adjusted for each other (Tables 1 and 2, column fibre and thiamine). Because, in women, the graphical representation of the associations with mean 2-h glucose values suggested the presence of effect-modification, we additionally evaluated the contribution of a product-term of thiamine and fibre intake to the models. In the next model (Tables 1 and 2, Model 2) adjustments were made for fasting glucose. In Model 3 additional adjustments were made for age, BMI, waist-to-hip ratio, alcohol consumption, smoking status and total fat and energy intake. We tested for the presence of effect-modification in the associations of thiamine and fibre intake with insulin resistance related laboratory measures.

Alcohol intake was divided into three categories to be adjusted for in the linear regression analyses. Firstly a zero alcohol intake was scored as 1 and a higher alcohol intake as 0 . Secondly an alcohol intake above $30 \mathrm{~g}$ per day was scored as 1 and a lower alcohol intake as 0 . These two dummy variables were then entered simultaneously in the linear regression analyses. Smoking status was divided into three categories: current-smokers, exsmokers and non-smokers. Intake of dietary fibre and thiamine were analysed in $\mathrm{g}$ per day and $\mathrm{mg}$ per day respectively. 
Table 1. Linear regression models of fibre intake $(25 \mathrm{~g} /$ day $)$ and thiamine intake $(1 \mathrm{mg} /$ day $)$ as determinants of 2 -h glucose in 1008 men

\begin{tabular}{|c|c|c|c|c|c|c|}
\hline Variable & $\begin{array}{l}\text { Fibre intake alone } \\
\beta(95 \% \mathrm{Cl})\end{array}$ & $p$-value & $\begin{array}{l}\text { Thiamine intake alone } \\
\beta(95 \% \mathrm{Cl})\end{array}$ & $p$-value & $\begin{array}{l}\text { Fibre and thiamine } \\
\beta(95 \% \mathrm{Cl})\end{array}$ & $p$-value \\
\hline $\begin{array}{l}\text { Model } 1^{\mathrm{a}} \\
\text { Fibre intake } \times 0.04 \\
\text { Thiamine intake }\end{array}$ & $-0.52(-0.83$ to -0.22$)$ & 0.0008 & $-0.73(-1.07$ to -0.39$)$ & $<0.0001$ & $\begin{array}{l}-0.14(-0.56 \text { to } 0.28) \\
-0.62(-1.09 \text { to }-0.15)\end{array}$ & $\begin{array}{l}0.51 \\
0.009\end{array}$ \\
\hline $\begin{array}{l}\text { Model } 2^{\mathrm{b}} \\
\text { Fibre intake } \times 0.04 \\
\text { Thiamine intake }\end{array}$ & $-0.38(-0.67$ to -0.09$)$ & 0.01 & $-0.71(-1.02$ to -0.39$)$ & $<0.0001$ & $\begin{array}{r}0.12(-0.28 \text { to } 0.51) \\
-0.79(-1.23 \text { to }-0.36)\end{array}$ & $\begin{array}{l}0.56 \\
0.0004\end{array}$ \\
\hline $\begin{array}{l}\text { Model } 3^{c} \\
\text { Fibre intake } \times 0.04 \\
\text { Thiamine intake }\end{array}$ & $-0.16(-0.51$ to & 0.41 & $-0.49(-0.97$ to -0.02$)$ & 0.04 & 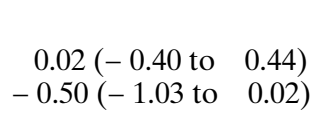 & $\begin{array}{l}0.93 \\
0.06\end{array}$ \\
\hline
\end{tabular}

The first column shows the slopes $(\beta), 95 \%$ confidence interval and $p$-values of three models of fibre intake as determinant of 2-h glucose. The second column shows these values for thiamine intake and the last column shows these values for three models in which fibre and thiamine intake are adjusted for each other. Fibre intake is always multiplied by 0.04 to get the slopes $(\beta)$ and $95 \%$ confidence intervals $(95 \% \mathrm{CI})$ obtained from analyses with fibre intake in the same order of magnitude as those obtained from analyses with thiamine intake.
${ }^{\text {a }}$ No adjustments are made

${ }^{\mathrm{b}}$ Models include fasting glucose as continuous variable

${ }^{c}$ Additionally adjusted for age, body mass index, waist-to-hip ratio, energy intake and total fat intake as continuous variables, and smoking habits (current smoker, ex-smoker, nonsmoker) and alcohol consumption (none, moderate, heavy) as categorized variables

Table 2. Linear regression models of fibre intake ( $25 \mathrm{~g} /$ day $)$ and thiamine intake $(1 \mathrm{mg} /$ day $)$ as determinants of 2 -h glucose in 1188 women

\begin{tabular}{|c|c|c|c|c|c|c|}
\hline Variable & $\begin{array}{l}\text { Fibre intake alone } \\
\beta(95 \% \mathrm{Cl})\end{array}$ & $p$-value & $\begin{array}{l}\text { Thiamine intake alone } \\
\beta(95 \% \mathrm{Cl})\end{array}$ & $p$-value & $\begin{array}{l}\text { Fibre and thiamine } \\
\beta(95 \% \mathrm{Cl})\end{array}$ & $p$-value \\
\hline $\begin{array}{l}\text { Model } 1^{\mathrm{a}} \\
\text { Fibre intake } \times 0.04 \\
\text { Thiamine intake } \\
\text { Thi } \times \text { Fib } \times 0.04\end{array}$ & $-0.36(-0.71$ to -0.01$)$ & 0.04 & $-0.38(-0.74$ to -0.01$)$ & 0.04 & $\begin{array}{r}-1.37(-2.56 \text { to }-0.18) \\
-1.36(-2.54 \text { to }-0.18) \\
1.04(0.06 \text { to } 2.02)\end{array}$ & $\begin{array}{l}0.02 \\
0.02 \\
0.04\end{array}$ \\
\hline $\begin{array}{l}\text { Model } 2^{\mathrm{b}} \\
\text { Fibre intake } \times 0.04 \\
\text { Thiamine intake } \\
\text { Thi } \times \text { Fib } \times 0.04\end{array}$ & $-0.14(-0.46$ to & 0.37 & $-0.33(-0.66$ to -0.01$)$ & 0.04 & 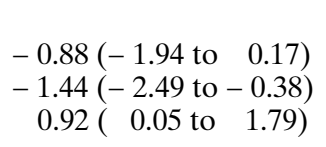 & $\begin{array}{l}0.10 \\
0.008 \\
0.04\end{array}$ \\
\hline $\begin{array}{l}\text { Model } 3^{\mathrm{c}} \\
\text { Fibre intake } \times 0.04 \\
\text { Thiamine intake } \\
\text { Thi } \times \text { Fib } \times 0.04\end{array}$ & $0.24(-0.16$ to 0.64$)$ & 0.23 & $0.21(-0.24$ to 0.66$)$ & 0.36 & 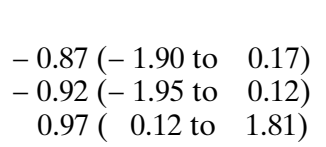 & $\begin{array}{l}0.10 \\
0.08 \\
0.03\end{array}$ \\
\hline
\end{tabular}

The first column shows the slopes $(\beta), 95 \%$ confidence interval and $p$-values of three models of fibre intake as determinant of 2-h glucose. The second column shows these values for thiamine intake and the last column shows these values for three models in which fibre and thiamine intake are adjusted for each other. In these models an additional product-term of thiamine intake and fibre intake $(\mathrm{Thi} \times \mathrm{Fib} \times 0.04)$ was entered because it appeared that thiamine intake and fibre intake modified each others effects with respect to 2-h glucose values. Fibre intake is always multiplied by 0.04 to get the slopes $(\beta)$

Alcohol intake was considered as a confounder because both an alcohol intake of $0 \mathrm{~g}$ per day and an alcohol intake of more than $30 \mathrm{~g}$ per day are known to adversely influence insulin sensitivity compared with a moderate intake [7, 26, 27]. Furthermore an alcohol intake exceeding $30 \mathrm{~g}$ per day is known to impair gastrointestinal thiamine absorption [10]. Therefore separate corrections were made for a zero alcohol intake and an alcohol intake of more than $30 \mathrm{~g}$ per day compared with an alcohol intake between 0 and $30 \mathrm{~g}$ per day. Smoking was corrected for because the inhalation of great amounts of free radicals and their scavenging [28], could inter- and $95 \%$ confidence intervals $(95 \% \mathrm{CI})$ obtained from analyses with fibre intake in the same order of magnitude as those obtained from analyses with thiamine intake.

${ }^{\text {a }}$ No adjustments are made

${ }^{\mathrm{b}}$ Models include fasting glucose as continuous variable

${ }^{c}$ Additionally adjusted for age, body mass index, waist-to-hip ratio, energy intake and total fat intake as continuous variables, and smoking habits (current smoker, ex-smoker, nonsmoker) and alcohol consumption (none, moderate, heavy) as categorized variables

fere with the biochemical action of thiamine [29] and because of its association with glucose intolerance [30, 31]. Energy intake was corrected for because effects of thiamine and fibre intake are usually considered with the amount of energy intake [10]. Intervention studies have shown that either insulin sensitivity or beta-cell function or both are improved by a high-fibre diet. These studies are confounded, however, by fat intake being decreased at the same time. Such a change in diet could be an alternative explaination for these findings [5]. Therefore, we also considered total daily fat intake to be a potential confounder. 
The difference between the 5th and the 95th centile of thiamine intake was approximately $1 \mathrm{mg}$ per day in men and women and for fibre intake this was approximately $25 \mathrm{~g}$ per day. In the further results sections and in Tables 1,2, 4 and 5 the associations of thiamine and fibre intake are analysed by means of regression analyses. To make the dose-effect estimates $(\beta)$ and their $95 \%$ confidence intervals $(95 \% \mathrm{CI})$ of these analyses comparable for thiamine and fibre intake, fibre intake ( $\mathrm{g}$ per day) was always multiplied by a factor 0.04 and thiamine intake (mg per day) by a factor 1 . In this way the $\beta$ and $95 \%$ CI values presented for fibre intake are to be interpreted as the estimated effect for a change of $25 \mathrm{~g}$ per day and those presented for thiamine intake as the estimated effect for a change of $1 \mathrm{mg}$ per day. Multiplication of fibre and thiamine intake by other factors would change the magnitude of the estimates of the effects, but not the $p$-values.

All statistical analyses were performed with the SPSS Release 6.1 statistical package. All multiple linear regression models were checked for their residuals to have a normal distribution using the logarithmically transformed insulin and triglyceride values instead of the untransformed ones. Values were considered statistically significant when two-sided $p$-values were below 0.05 .

\section{Results}

Population characteristics and intake of dietary fibres and thiamine. Population characteristics are shown in Table 3. Dietary intake of thiamine and fibres were correlated in men and in women (Fig.2). Dietary intake of thiamine was below the recommended daily allowance (RDA) of $1 \mathrm{mg}$ per day [10] in $25.1 \%$ of the men and in $46.0 \%$ of the women. Thiamine intake ranged from 0.29 to $2.89 \mathrm{mg}$ per day in men and from 0.33 to $2.53 \mathrm{mg}$ per day in women. Fibre intake ranged from 6.7 to $92.2 \mathrm{~g}$ per day in men and from 7.7 to $60.4 \mathrm{~g}$ per day in women. In men, the 5 th centile of fibre intake was $15.8 \mathrm{~g}$ per day and the 95 th was $42.8 \mathrm{~g}$ per day. In women these values were $15.6 \mathrm{~g}$ per day and $38.3 \mathrm{~g}$ per day respectively. The 5 th centile of thiamine intake in men was $0.73 \mathrm{mg}$ per day and the 95th was $1.74 \mathrm{mg}$ per day. In women these values were $0.67 \mathrm{mg}$ per day and $1.52 \mathrm{mg}$ per day respectively.

Variation of 2-h glucose in tertiles of fibre and thiamine intake. In men variation of fibre intake within tertiles of thiamine intake was not visually associated with changes in 2-h glucose values. In contrast, in all three tertiles of fibre intake 2 -h glucose seemed to fall with increasing thiamine intake. In women, fibre intake was inversely associated with 2 -h glucose in the lowest tertile of thiamine intake. In the highest tertile of thiamine intake an opposite association of fibre intake with 2-h glucose was apparent. Likewise, thiamine intake was inversely associated with 2-h glucose in the lowest tertile of fibre intake and an opposite association between these two was present in the highest tertile of fibre intake (Fig.1). Because these associations are highly suggestive of the existence of
Table 3. Characteristics of study subjects

\begin{tabular}{|c|c|c|}
\hline & $\begin{array}{l}\text { Men } \\
(n=1008)\end{array}$ & $\begin{array}{l}\text { Women } \\
(n=1188)\end{array}$ \\
\hline Age, years & $60.9 \pm 7.1$ & $61.5 \pm 7.3$ \\
\hline Body mass index, $\mathrm{kg} / \mathrm{m}^{2}$ & $26.1 \pm 2.9$ & $26.6 \pm 3.8$ \\
\hline Waist-hip ratio & $0.95 \pm 0.06$ & $0.84 \pm 0.07$ \\
\hline Body weight, kg & $80.2 \pm 10.3$ & $70.7 \pm 10.7$ \\
\hline Fasting glucose, $\mathrm{mmol} / \mathrm{l}$ & $5.54 \pm 0.58$ & $5.37 \pm 0.58$ \\
\hline 2-hour glucose, $\mathrm{mmol} / \mathrm{l}$ & $5.44 \pm 1.73$ & $5.75 \pm 1.69$ \\
\hline Dietary thiamine, $\mathrm{mg} /$ day & $1.2 \pm 0.3$ & $1.1 \pm 0.3$ \\
\hline Dietary fibers, g/day & $28.7 \pm 8.7$ & $26.2 \pm 6.9$ \\
\hline Dietary Kcal, × 1000 & $2.34 \pm 0.59$ & $1.85 \pm 0.47$ \\
\hline Smoking, current/ex/never, \% & $40 / 45 / 15$ & $28 / 23 / 49$ \\
\hline Alcohol intake, $\mathrm{g} /$ day $^{\mathrm{a}}$ & $8.3[2.2-17.7]$ & $2.1[0-7.4]$ \\
\hline Fasting insulin, $\mathrm{pmol} / \mathrm{l}^{\mathrm{a}}$ & $76[60-98]$ & 75 [59-97] \\
\hline 2-hour insulin, $\mathrm{pmol} / \mathrm{l}^{\mathrm{a}}$ & 352 [195-610] & 413 [268-680] \\
\hline Fasting triglycerides, $\mathrm{mmol} / \mathrm{l}^{\mathrm{a}}$ & $1.4[1.1-2.0]$ & $1.3[1.0-1.8]$ \\
\hline Cholesterol, $\mathrm{mmol} / \mathrm{l}$ & $6.43 \pm 1.11$ & $6.87 \pm 1.16$ \\
\hline HDL-cholesterol, mmol/l & $1.19 \pm 0.31$ & $1.47 \pm 0.36$ \\
\hline
\end{tabular}

All figures are given as means \pm standard deviation, except those marked with an ${ }^{\text {a }}$, which are given as median and in brackets the $25^{\text {th }}$ and $75^{\text {th }}$ centile

effect-modification, we created a product-term of thiamine and fibre intake and analysed its relevance by means of linear regression analysis.

2-h glucose in men. For men, the results of crude (univariate) linear regression analyses of the associations observed in Figure 1 are presented in Table 1 . In these models fibre and thiamine were strongly associated with 2-h glucose. The association between fibre intake and 2-h glucose, however, completely disappeared when adjusted for thiamine intake. As could be expected from the visualisation of 2-h glucose values in tertiles of thiamine and fibre intake, the association between thiamine intake and 2-h glucose was almost independent of fibre intake. Further analysis with a product-term of thiamine intake and fibre intake did not show any effect-modification in men (data not shown).

The possibility that either fibre or thiamine intake was associated with 2-h glucose because of an effect on fasting glucose was investigated in Model 2. After adjustment for fasting glucose, the association between fibre intake and 2-h glucose became less strong, but remained statistically significant. After additional adjustment for thiamine intake, however, the association between fibre intake and 2-h glucose disappeared. In contrast, the association between thiamine intake and 2-h glucose was independent of fasting glucose and fibre intake.

The association between fibre intake and 2-h glucose disappeared after additional adjustment for potential confounders (Table 1, column fibre intake alone). Again in contrast, the association between thiamine intake and 2-h glucose persisted after additional adjustment for the same potential confounders (Table 1, column thiamine intake alone). Additional 

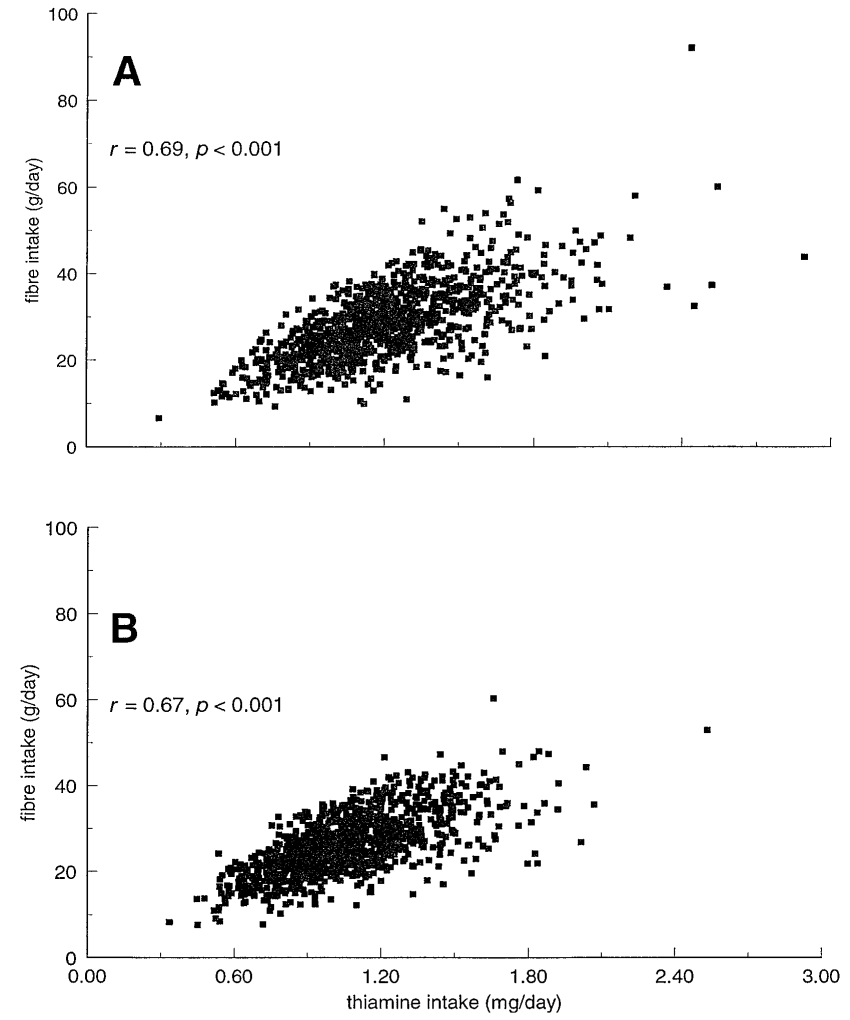

Fig. 2A, B. Scatter plot of fibre versus thiamine intake in 1008 men $(\mathbf{A})$ and 1188 women (B)

adjustment for fibre intake did not much affect this association between thiamine intake and 2-h glucose (Table 1, column fibre and thiamine). No sign of effect-modification was encountered in men (data not shown).

$2-h$ glucose in women. For women, the results of crude (univariate) linear regression analyses of the associations are presented in Table 2 (columns fibre intake alone and thiamine intake alone, Model 1). In these models 2-h glucose values were inversely associated with fibre intake and thiamine intake. As was suspected from the visualisation of mean 2-h glucose values in tertiles of thiamine and fibre intake (Fig.1), there was effect-modification between the respective associations of thiamine intake and fibre intake with 2-h glucose, as reflected by a statistically significant product-term of thiamine and fibre intake $($ Thi $\times$ Fib $\times 0.04)$ in the model (Table 2 , column fibre and thiamine, Model 1). The product-term of thiamine and fibre intake was independent of fasting glucose (Table 2, column fibre and thiamine, Model 2 ), and independent of further adjustment for age, BMI, waist-to-hip ratio, total fat intake, energy intake, smoking habits and alcohol consumption (Table 2, column fibre and thiamine, Model 3), as also indicated by only small changes of the estimates of the regression coefficients. The effect-modification acts in such a way that changes in thiamine intake have a great impact on 2-h glucose when fibre intake is low, whereas this impact gradually disappears with increasing fibre intake. For example from the equation in Table 2 (column fibre and thiamine, Model 2) it can be calculated that in women a rise of thiamine intake from the 5th to the 95th centile, with the fibre intake fixed at the 5th centile, would cause 2-h glucose to fall with $0.74 \mathrm{mmol} / \mathrm{l}$, whereas the same rise in thiamine intake with the fibre intake fixed at the 95th centile would cause 2-h glucose to fall with only $0.03 \mathrm{mmol} / \mathrm{l}$. Apparently, the association between thiamine intake and 2-h glucose in women is much the same as in men, but modified by fibre intake.

Markers of insulin sensitivity. In men (Table 4), fibre intake seemed to be negatively associated with fasting glucose, total cholesterol and fasting triglycerides, independent of age. Thiamine intake did not show any significant association with any of these variables. After additional adjustment for BMI, waist-to-hip ratio, total fat intake, energy intake, smoking habits and alcohol consumption only the inverse association of fibre intake with fasting triglycerides persisted $(\beta=-0.11,95 \%$ CI -0.22 to $-0.01, p=0.04)$.

In women (Table 5), fibre intake was negatively associated with fasting glucose, total cholesterol and fasting insulin, but not with fasting triglycerides. Thiamine intake was not negatively associated with any insulin resistance related laboratory measure. After additional adjustment for BMI, waist-to-hip ratio, total fat intake, energy intake, smoking habits and alcohol consumption only the inverse association of fibre intake with fasting insulin persisted $(\beta=-0.13,95 \%$ CI -0.24 to $-0.02, p=0.02$ ).

In contrast to the analyses for 2-h glucose in women no evidence for effect-modification between thiamine intake, fibre intake and the insulin resistance related laboratory measures could be found in men or in women (data not shown). Blood pressure was not related to either thiamine or fibre intake (data not shown).

\section{Discussion}

In this study we confirm results of previous studies of an inverse association between fibre intake and 2-h glucose disappearing after adjustment for potential confounders [2-7]. An important part of the univariate association between fibre intake and 2-h glucose existed because of an inverse association between fibre intake and fasting glucose concentrations, probably as a result of improved insulin sensitivity $[3,5,7$, 9].

The other part of the univariate association between fibre intake and 2-h glucose appeared to exist because of the close correlation between fibre and 
Table 4. Linear regression analyses of fibre intake ( $25 \mathrm{~g} /$ day $)$ and thiamine intake $(1 \mathrm{mg} /$ day $)$ as determinants of fasting plasma glucose, lipids and insulin levels in 1008 men

\begin{tabular}{|c|c|c|c|c|}
\hline Dependent variable & $\begin{array}{l}\text { Fibre intake } \times 0.04 \\
\beta(95 \% \mathrm{Cl})^{\mathrm{a}}\end{array}$ & $p$-value & $\begin{array}{l}\text { Thiamine intake } \\
\beta(95 \% \mathrm{Cl})^{\mathrm{a}}\end{array}$ & $p$-value \\
\hline Fasting glucose (mmol/l) & $-0.13(-0.24$ to -0.03$)$ & 0.01 & $-0.00(-0.12$ to 0.11$)$ & 0.95 \\
\hline Total cholesterol (mmol/l) & $-0.23(-0.43$ to -0.04$)$ & 0.02 & $-0.00(-0.22$ to 0.23$)$ & 0.99 \\
\hline Triglycerides ${ }^{\mathrm{b}}(\mathrm{mmol} / \mathrm{l})$ & $-0.14(-0.23$ to -0.06$)$ & 0.0006 & $-0.07(-0.17$ to 0.02$)$ & 0.13 \\
\hline HDL-cholesterol (mmol/l) & $-0.02(-0.08$ to 0.04$)$ & 0.50 & $-0.02(-0.08$ to 0.05$)$ & 0.60 \\
\hline Fasting insulin ${ }^{\mathrm{b}}(\mathrm{pmol} / \mathrm{l})$ & $-0.07(-0.15$ to 0.01$)$ & 0.07 & $-0.05(-0.14$ to 0.04$)$ & 0.24 \\
\hline 2-h insulin ${ }^{\mathrm{b}}(\mathrm{pmol} / \mathrm{l})^{\mathrm{c}}$ & $-0.28(-0.59$ to 0.03$)$ & 0.07 & $-0.32(-0.67$ to 0.04$)$ & 0.08 \\
\hline
\end{tabular}

a All values are adjusted for age (continuous variable)

b Transformed to its natural logarithm for analysis. If triglycerides are transformed back to their original scale, the age adjusted association between fasting triglycerides and fibre

intake indicates that a $25 \mathrm{~g}$ /day increase in fibre intake would result in a fall of fasting triglycerides with a factor $0.87(0.79$ to 0.94$)[\beta(95 \% \mathrm{Cl})]$

${ }^{\mathrm{c}} n=242$

Table 5. Linear regression analyses of fibre intake ( $25 \mathrm{~g} / \mathrm{day})$ and thiamine intake $(1 \mathrm{mg} /$ day $)$ as determinants of fasting plasma glucose, lipids and insulin levels in 1188 women

\begin{tabular}{|c|c|c|c|c|}
\hline Dependent variable & $\begin{array}{l}\text { Fibre intake } \times 0.04 \\
\beta(95 \% \mathrm{Cl})^{\mathrm{a}}\end{array}$ & $p$-value & $\begin{array}{l}\text { Thiamine intake } \\
\beta(95 \% \mathrm{Cl})\end{array}$ & $p$-value \\
\hline Fasting glucose $(\mathrm{mmol} / \mathrm{l})$ & $-0.14(-0.26$ to -0.02$)$ & 0.02 & $0.02(-0.10$ to 0.15$)$ & 0.73 \\
\hline Total cholesterol $(\mathrm{mmol} / \mathrm{l})$ & $-0.31(-0.55$ to -0.07$)$ & 0.01 & $-0.16(-0.41$ to 0.10$)$ & 0.22 \\
\hline Triglycerides $^{\mathrm{b}}(\mathrm{mmol} / \mathrm{l})$ & $-0.03(-0.12$ to 0.05$)$ & 0.47 & $0.04(-0.06$ to 0.13$)$ & 0.46 \\
\hline HDL-cholesterol $(\mathrm{mmol} / \mathrm{l})$ & $0.01(-0.07$ to 0.08$)$ & 0.85 & $0.03(-0.05$ to 0.11$)$ & 0.41 \\
\hline Fasting insulin ${ }^{\mathrm{b}}(\mathrm{pmol} / \mathrm{l})$ & $-0.10(-0.18$ to -0.01$)$ & 0.03 & $0.01(-0.08$ to 0.10$)$ & 0.81 \\
\hline 2-h insulin ${ }^{\mathrm{b}}(\mathrm{pmol} / \mathrm{l})^{\mathrm{c}}$ & $-0.22(-0.53$ to 0.09$)$ & 0.16 & $-0.06(-0.39$ to 0.27$)$ & 0.73 \\
\hline
\end{tabular}

${ }^{a}$ All values are adjusted for age (continuous variable)

$\mathrm{b}$ Transformed to its natural logarithm for analysis

${ }^{\mathrm{c}} n=264$

thiamine intake. After adjustment for thiamine intake and fasting glucose no association between fibre intake and 2-h glucose was found. These results suggest that thiamine intake is an important determinant of glucose tolerance and that fibre intake, in this respect, serves as a marker of thiamine intake.

Although our study was not designed to ascertain by which mechanisms thiamine intake might modulate post-load glucose values, some speculations can be made. Thiamine deficiency impairs glucose oxidation $[14,15]$ which is possibly reflected by a lower glucose uptake after glucose loading. Thiamine intake was, however, not associated with fasting glucose, fasting triglycerides, fasting insulin and 2-h insulin, thus an apparent effect on insulin sensitivity seems not to be involved [32, 33]. Thiamine deficiency has been shown to be associated with impaired beta-cell function [16-19]. This could contribute to an impaired post-load glucose handling in thiamine deficiency. Beta-cells require GSH and ATP for the synthesis and secretion of insulin [34]. Thiamine is involved in the production of GSH and ATP from oxidation of glucose in the pentose phosphate shunt and the citric acid cycle [35]. An impairment in reduced glutathione and ATP production could especially become unmasked when metabolic requirements are high $[35,36]$. This seems to be the case when thiamine deficient beta-cells are exposed to a glucose load. Our finding that thiamine intake and 2-h insulin were not associated is not incongruous with this, as 2-h insulin concentrations are strongly associated with 2-h glucose values, whereas those of $30 \mathrm{~min}$ insulin reflect beta-cell responsiveness to a glucose load and have been shown to determine the 2-h glucose values [37]. Unfortunately, this measurement was not made in the Hoorn Study.

In women the association between thiamine intake and 2-h glucose was more complex than in men. It seems to be modified by fibre intake. Adjustment for fibre intake and a product-term of thiamine and fibre intake was necessary to disclose an association between thiamine intake and 2-h glucose that was comparable to that in men. Although there is no clear explanation for this sex difference, it can be speculated that sex-hormones are involved, especially when considering that dietary fibres are an important source of phytoestrogens, $17-\beta$-estradiol like compounds [38]. The concentrations of $17-\beta$-estradiol are lower in postmenopausal females than in males of the same age [39-41]. Deficiency of 17- $\beta$-estradiol seems to play a part in the deterioration of glucose homeostasis in elderly women [42], that can be treated by $17-\beta$-estradiol supplementation [43]. Possibly treatment of $17-\beta$-estradiol deficiency by a $17-\beta$-estradiol like effect of phytoestrogens modifies the effect of thiamine on glucose tolerance in women but not in men.

In summary, this cross-sectional analysis from the Hoorn Study population suggests that the effect of fi- 
bre intake on 2-h glucose is exerted for a small part through an effect on fasting glucose (related to an improvement of insulin sensitivity), but that the greater part has to be attributed to concomitant intake of thiamine and that fibre intake serves as a marker of thiamine intake. As we found a linear relation in men and in women, it is likely that thiamine intake modulates glucose tolerance even when intake levels exceed current dietary recommendations. An important consequence of this study is that future intervention studies that investigate the effect of dietary fibres on fasting glucose and post-load glucose metabolism should consider whether differences in thiamine content of different fibre sources interfere with the actual effect of the dietary fibre under investigation. Another consequence would be that epidemiologic studies should consider thiamine intake as a potential confounder in possible associations with post load-glucose values.

Although an association of thiamine intake with 2-h glucose values is biologically plausible, the limitations of our cross-sectional study should be considered before drawing conclusions about the actual existence of a causal relation between thiamine intake and glucose tolerance. Possibly fibres or thiamine serve, at least partly, as surrogates for other micronutrients such as chromium, vanadium, magnesium and manganese, that are known to affect glucose tolerance [44-48]. We were unable to assess the intake of these micronutrients with our questionnaire because they are not available in the Dutch Food Composition Table. Therefore we could not adjust for these potential confounders.

\section{References}

1. Anderson JW (1992) Dietary fiber and diabetes: what else do we need to know? Diabetes Res Clin Pract 17: 71-73

2. Munoz JM, Sandstead HH, Jacob RA (1979) Effects of dietary fiber on glucose tolerance of normal men. Diabetes 28: 496-502

3. Hallfrisch J, Tobin JD, Muller DC, Andres R (1988) Fiber intake, age, and other coronary risk factors in men of the Baltimore Longitudinal Study (1959-1975). J Gerontol 43: M64-M68

4. Crapo PA, Reaven G, Olefsky J (1977) Postprandial plasma-glucose and -insulin responses to different complex carbohydrates. Diabetes 26: 1178-1183

5. Lovejoy J, DiGirolamo M (1992) Habitual dietary intake and insulin sensitivity in lean and obese adults. Am J Clin Nutr 55: 1174-1179

6. Feskens EJ, Kromhout D (1990) Habitual dietary intake and glucose tolerance in euglycaemic men: the Zutphen Study. Int J Epidemiol 19: 953-959

7. Mooy JM, Grootenhuis PA, de Vries H et al. (1995) Prevalence and determinants of glucose intolerance in a Dutch caucasian population. The Hoorn Study. Diabetes Care 18: 1270-1273

8. Brodribb AJ, Humphreys DM (1976) Diverticular disease: three studies. Part III - Metabolic effect of bran in patients with diverticular disease. BMJ 1: 428-430
9. Fukagawa NK, Anderson JW, Hageman G, Young VR, Minaker, KL (1990) High-carbohydrate, high-fiber diets increase peripheral insulin sensitivity in healthy young and old adults. Am J Clin Nutr 52: 524-528

10. Baum RA, Iber FL (1984) Thiamin - the interaction of aging, alcoholism, and malabsorption in various populations. World Rev Nutr Diet 44: 85-116

11. Butterworth RF (1993) Maternal thiamine deficiency. A factor in intrauterine growth retardation. Ann N Y Acad Sci 678: 325-329

12. McCandless DW, Schenker S, Cook M (1968) Encephalopathy of thiamine deficieny: studies of intracerebral mechanisms. J Clin Invest 47: 2268-2280

13. Hsu JM, Chow BF (1960) Effect of thiamine deficiency on glutathione contents of erythrocytes and tissues in the rat. Proc Soc Exp Biol Med 104: 178-180

14. Hakim AM, Carpenter S, Pappius HM (1983) Metabolic and histological reversibility of thiamine deficiency. J Cerebr Blood Flow Metab 3: 468-477

15. Hakim AM, Pappius HM (1981) The effect of thiamine deficiency on local cerebral glucose utilization. Ann Neurol 9: 334-339

16. Rathanaswami P, Pourany A, Sundaresan R (1991) Effects of thiamine deficiency on the secretion of insulin and the metabolism of glucose in isolated rat pancreatic islets. Biochem Int 25: 577-583

17. Rathanaswami P, Sundaresan R (1991) Effects of thiamine deficiency on the biosynthesis of insulin in rats. Biochem Int 24: 1057-1062

18. Rathanaswami P, Sundaresan R (1989) Modulation of A and $\mathrm{B}$ cell functions by tolbutamide and arginine in the pancreas of thiamine-deficient rats. Biochem Int 19: 793-802

19. Rathanaswami P, Sundaresan R (1988) Effects of insulin secretagogues on the secretion of insulin during thiamine deficiency. Biochem Int 17: 523-528

20. Prasannan KG, Kondaiah MS, Kalyanasundaram S, Sundaresan, R (1973) Studies on biochemical alterations in thiamine deficiency. I. Levels of certain blood constituents and glucose tolerance in normal \& thiamine deficient rats. Indian J Biochem Biophys Methods 10: 119-122

21. Iwata H, Baba A, Baba T, Nishikawa T (1974) Glucose intolerance in thiamine-deficient rats. J Pharm Pharmacol 26: 707-710

22. Hoorn RK, Flikweert JP, Westerink D (1975) Vitamin B-1, B-2 and B-6 deficiencies in geriatric patients, measured by coenzyme stimulation of enzyme activities. Clin Chim Acta 61: 151-162

23. Mooy JM, Grootenhuis PA, de Vries H et al. (1996) Intraindividual variation of glucose, specific insulin and proinsulin concentrations measured by two oral glucose tolerance tests in a general Caucasian population: the Hoorn Study. Diabetologia 39: 298-305

24. Nijpels G, Popp-Snijders C, Kostense PJ, Bouter LM, Heine RJ (1996) Fasting proinsulin and 2-h post-load glucose levels predict the conversion to NIDDM in subjects with impaired glucose tolerance: the Hoorn Study. Diabetologia 39: $113-118$

25. Grootenhuis PA, Westenbrink S, Sie CM, de Neeling JN, Kok FJ, Bouter LM (1995) A semiquantitative food frequency questionnaire for use in epidemiologic research among the elderly: validation by comparison with dietary history. J Clin Epidemiol 48: 859-868

26. Facchini F, Chen YD, Reaven GM (1994) Light-to-moderate alcohol intake is associated with enhanced insulin sensitivity. Diabetes Care 17: 115-119

27. Holbrook TL, Barrett-Connor E, Wingard DL (1990) A prospective population-based study of alcohol use and 
non- insulin-dependent diabetes mellitus. Am J Epidemiol 132: 902-909

28. Noronha-Dutra AA, Epperlein MM, Woolf N (1993) Effect of cigarette smoking on cultured human endothelial cells. Cardiovasc Res 27: 774-778

29. Bakker SJL, Yin M, Kootstra G (1996) Tissue thiamine and carnitine deficiency as a possible cause of acute tubular necrosis after renal transplantation. Transplant Proc 28: 314-315

30. Zavaroni I, Bonini L, Gasparini P et al. (1994) Cigarette smokers are relatively glucose intolerant, hyperinsulinemic and dyslipidemic. Am J Cardiol 73: 904-905

31. Frati AC, Iniestra F, Ariza CR (1996) Acute effect of cigarette smoking on glucose tolerance and other cardiovascular risk factors. Diabetes Care 19: 112-118

32. Reaven GM (1988) Banting lecture 1988. Role of insulin resistance in human disease. Diabetes 37: 15951607

33. Reaven GM (1995) Pathophysiology of insulin resistance in human disease. Physiol Rev 75: 473-486

34. Verspohl EJ, Kaiser P, Wahl M, Ammon HP (1988) Decreased insulin secretory response of pancreatic islets during culture in the presence of low glucose is associated with diminished $45 \mathrm{Ca} 2$ + net uptake, NADPH/NAD$\mathrm{P}+$ and GSH/GSSG ratios. Life Sci 43: 209-219

35. Bakker SJL, Heine RJ, Gans ROB (1997) Thiamine may indirectly act as an antioxidant. Diabetologia 40: 741-742

36. Bakker SJL, ter Maaten JC, Hoorntje SJ, Gans ROB (1997) Protection against cardiovascular collaps in an alcoholic patient with thiamine deficiency by concomitant alcoholic ketoacidosis. J Intern Med 242: 179-183

37. Mitrakou A, Kelley D, Mokan M et al. (1992) Role of reduced suppression of glucose production and diminished early insulin release in impaired glucose tolerance. $\mathrm{N}$ Engl J Med 326: 22-29

38. Knight DC, Eden JA (1996) A review of the clinical effects of phytoestrogens. Obstet Gynecol 87: 897-904
39. Wakatsuki A, Sagara Y (1995) Lipoprotein metabolism in postmenopausal and oophorectomized women. Obstet Gynecol 85: 523-528

40. Cauley JA, Gutai JP, Kuller LH, Powell JG (1991) Reliability and interrelations among serum sex hormones in postmenopausal women. Am J Epidemiol 133: 50-57

41. Kuller LH, Gutai JP, Meilahn E, Matthews KA, Plantinga P (1990) Relationship of endogenous sex steroid hormones to lipids and apoproteins in postmenopausal women. Arteriosclerosis 10: 1058-1066

42. Senoz S, Direm B, Gulekli B, Gokmen O (1996) Estrogen deprivation, rather than age, is responsible for the poor lipid profile and carbohydrate metabolism in women. Maturitas 25: 107-114

43. Brussaard HE, Gevers-Leuven JA, Frolich M, Kluft C, Krans HJ (1997) Short-term oestrogen replacement therapy improves insulin resistance, lipids and fibrinolysis in postmenopausal women with NIDDM. Diabetologia 40: 843-849

44. Anderson RA (1997) Nutritional factors influencing the glucose/insulin system: chromium. J Am Coll Nutr 16: 404-410

45. Cohen N, Halberstam M, Shlimovich P, Chang CJ, Shamoon H, Rossetti L (1995) Oral vanadyl sulfate improves hepatic and peripheral insulin sensitivity in patients with non-insulin-dependent diabetes mellitus. J Clin Invest 95: 2501-2509

46. Paolisso G, Passariello N, Pizza G et al. (1989) Dietary magnesium supplements improve B-cell response to glucose and arginine in elderly non-insulin dependent diabetic subjects. Acta Endocrinol 121: 16-20

47. Nadler JL, Buchanan T, Natarajan R, Antonipillai I, Bergman R, Rude R (1993) Magnesium deficiency produces insulin resistance and increased thromboxane synthesis. Hypertension 21: 1024-1029

48. Hurley LS, Keen CL, Baly DL (1984) Manganese deficiency and toxicity: effects on carbohydrate metabolism in the rat. Neurotoxicology 5: 97-104 